\title{
The Agricultural Productivity Gap in Europe
}

\author{
Wenbiao Cai and Manish Pandey
}

Department of Economics Working Paper Number: 2013-05

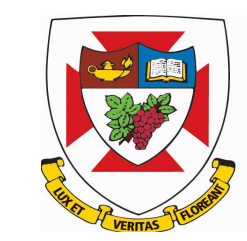

\section{THE UNIVERSITY OF WINNIPEG}

\author{
Department of Economics \\ 515 Portage Avenue
}

Winnipeg, R3B 2E9

Canada

This working paper is available for download at: http://ideas.repec.org/s/win/winwop.html 


\title{
The Agricultural Productivity Gap in Europe
}

\author{
Wenbiao Cai* Manish Pandey ${ }^{\dagger}$
}

December 2013

\begin{abstract}
For fifteen European countries over the 1970-2004 period we establish that there is a large and persistent agricultural productivity gap, the ratio of labor productivity in non-agriculture to that in agriculture. Correcting for under-reporting of selfemployment income in both agriculture and non-agriculture significantly reduces the measured agricultural productivity gap. For countries with information on years of school and experience at the sector level, we also find substantially higher human capital in non-agriculture than in agriculture. Our findings suggest that measured labor productivity differences between agriculture and non-agriculture in European countries are not an indicator of resource misallocation, but possibly an artifact of mismeasurement of value added and sectoral differences in human capital.
\end{abstract}

JEL Codes: E01; O47; O52; Q10

keywords: Productivity Gap; Agriculture; Non-agriculture; Europe

For helpful comments and suggestions, we thank Xiao Wang, Chih Ming Tan, Cullen Goenner, Kwan Yong Lee, and seminar participants at the University of North Dakota. All errors are our own.

*Department of Economics, University of Winnipeg. 515 Portage Avenue, Winnipeg, Manitoba, R3B2E9, Canada. Phone: 1-204-258-2984; fax: 1-204-772-4183; email: we.cai@uwinnipeg.ca.

${ }^{\dagger}$ Department of Economics, University of Winnipeg. 515 Portage Avenue, Winnipeg, Manitoba, R3B2E9, Canada. Phone: 1-204-786-9289; fax: 1-204-772-4183; email: m.pandey@uwinnipeg.ca. 


\section{Introduction}

A large and growing literature has focused on cross-country differences in labor productivity of agriculture as a key step towards understanding income differences across countries. ${ }^{1}$ It is, however, equally important to understand productivity differences between agriculture and non-agriculture within a country. The agricultural productivity gap, defined as the ratio of labor productivity in non-agriculture to that in agriculture, is as large as a factor 10 for countries in the bottom decile of the world income distribution (Caselli, 2005). At face value, the existence of such large agricultural productivity gaps suggests that labor is misallocated; and moving labor out of agriculture to non-agriculture would increase aggregate output without changes in factors of production. ${ }^{2}$

This paper builds on two recent papers on the agricultural productivity gap. ${ }^{3}$ For a large set of developing countries, Gollin, Lagakos, and Waugh (2013) construct careful measures of the agricultural productivity gap. They conclude that since micro data from household surveys lead to productivity gaps of similar magnitudes, measurement errors in national accounts are not likely to account for much of the productivity gap. Using data across US states, Herrendorf and Schoellman (2012) establish that even in the US the agricultural productivity gap is large. They argue that a substantial fraction of the agricultural productivity gap in the US is due to under-measurement of value added in agriculture. However, "whether this type of mismeasurement is equally at play in countries outside the United States, [...], is an open question." (Gollin et al., 2013, p.3). We contribute to this literature by documenting the agricultural productivity gaps for fifteen European countries and investigating whether

\footnotetext{
${ }^{1}$ Leading explanations are unmeasured home production (Gollin, Parente, and Rogerson, 2004), suboptimal use of intermediate input (Restuccia, Yang, and Zhu, 2008; Donovan, 2013), inefficient farm size (Cai, 2012; Adamopoulos and Restuccia, 2013), transportation costs (Gollin and Rogerson, 2010; Adamopoulos, 2011), and selection of workers (Lagakos and Waugh, 2013).

${ }^{2}$ For example, Vollrath (2009) found that differences in the degree of resources misallocation between agriculture and non-agriculture can account for one-third of the cross-country income differences.

${ }^{3}$ Another related paper is Young (2013), which uses micro-level data to establish large rural-urban gaps in consumption for developing countries.
} 
mismeasurement of value added can account for these gaps.

Our primary source of data is EU-KLEMS, which is a compilation of national accounts of European countries at a 3-digit industry level. The data set is supplemented with, when available, labor force surveys to provide additional information on hours of work, education, and demographics. These data span over a period of 35 years from 1970 to 2004. To ensure comparability across countries, we restrict our sample to include countries that were members of the European Union in 1995 (EU15). These countries have longer, uninterrupted series of data, and constitute a representative sample of developed countries in Europe. ${ }^{4}$

We document significant agricultural productivity gaps in Europe. Measured as the ratio of value added per worker in non-agriculture to that in agriculture, the average agricultural productivity gap is roughly a factor 2 . The gap in value added per worker is not due to more hours worked in non-agriculture. In fact, when measured as the ratio of value added per hour, the average productivity gap increases to 2.2. The agricultural productivity gaps we find for Europe are similar in magnitude to those documented by Herrendorf and Schoellman (2012) for US states, and those by Gollin et al. (2013) for developed countries in their sample. We provide two additional findings. First, the agricultural productivity gaps in Europe were persistent over the 35 year period. Second, despite the countries in our sample sharing similar levels of economic development, there are large differences in the agricultural productivity gap across countries: it ranges from as low as 1.3 to as high as $4.5^{5}$

We next examine whether the agricultural productivity gaps are due to mismeasurement of value added in national income accounts. To identify the measurement problem, we use an accounting identity. ${ }^{6}$ With minimum assumptions on production technology, the accounting identity suggests that the gap in value added per hour between agriculture and non-agriculture should be roughly 70 percent of the wage gap, the ratio of non-agriculture

\footnotetext{
${ }^{4}$ According to EUROSTAT, in 2011 these countries produce 92 percent of total GDP in Europe.

${ }^{5}$ The range of variation is similar to those found in Herrendorf and Schoellman (2012) across US states.

${ }^{6}$ This approach is used in Herrendorf and Schoellman (2012) and we follow it here.
} 
and agriculture average wages. We find that this accounting identity does not hold in the data. Specifically, the ratio of the gap in value added per hour to the wage gap is significantly larger than 0.7 for all countries in our sample. Given the extensive evidence documenting under-reporting of self-employment income for European countries, we examine whether this kind of under-reporting could explain why the accounting identity fails to hold in the data. $^{7}$ Since self-employment as a fraction of the labor force is higher in agriculture than in non-agriculture, under-reporting of self-employment income would downward bias measured value added more in agriculture than in non-agriculture.

Using information on the degree of under-reporting documented in the literature and data on hours worked by self-employed in agriculture and non-agriculture, we adjust upward the self-employment component of value added in both sectors and recompute value added per hour and the agricultural productivity gap. We find that this adjustment significantly reduces the gap in value added per hour between agriculture and non-agriculture: for our preferred measure of under-reporting of self-employed income, the gap reduces from 2.2 to 1.2. Consistent with the accounting identity, the adjusted value added per hour gap is about 70 percent of the wage gap. This exercise leads us to conclude that under-measurement of value added in agriculture, a concern raised in Herrendorf and Schoellman (2012) for the US, is also a problem with the national income accounts of European countries.

Lastly, we establish that there are substantial differences in human capital between agriculture and non-agriculture. For each country with available information, we compute years of schooling and experience in agriculture and non-agriculture using data from EU-KLEMS. We estimate returns to schooling and experience for agriculture and non-agriculture separately using data for the US from the March supplement to 2012 Current Population Survey

\footnotetext{
${ }^{7}$ Under-reporting of self-employment income in different European countries has been documented by a number of studies. See Pissarides and Weber (1989) for evidence of under-reporting in Britain; Matsaganis and Flevotomou (2010) in Greece; and Fiorio and D'Amuri (2005) in Italy.
} 
(CPS). ${ }^{8}$ The estimated returns are then used to compute human capital in agriculture and non-agriculture for countries in our sample. Across countries, human capital on average is 20 percent higher in non-agriculture than in agriculture. The sectoral differences in human capital are similar in magnitude to the agricultural productivity gap after adjusting for under-reporting of self-employment income.

The remaining of the paper is organized as follows. Section 2 describes the data and establishes the agricultural productivity gaps for Europe. Section 3 explores whether these productivity gaps can be explained by measurement errors and human capital. Section 4 concludes.

\section{Agricultural Productivity Gap}

\subsection{Data Description}

Our main source of data is the EU-KLEMS database (version March 2007). ${ }^{9}$ Detailed description of the database is provided in O'Mahony and Timmer (2009). The database is a compilation of industry-level input-output accounts for major European countries that spans over a period of 35 years from 1970 to 2004. The primary focus of the EU-KLEMS project is productivity analysis at the industry level. Industries are classified according to the European NACE revision 1 classification. For each industry and each year, the data set provides measures of value added, size of employment, hours of work, and demographics. When available, EU-KLEMS is supplemented with labor force surveys, which provides additional information on wage and education of workers at the industry level.

Given the scope and coverage of the EU-KLEMS database, a concern is comparability across countries and over time. We provide two arguments to alleviate the concern. First,

\footnotetext{
${ }^{8}$ Lack of access to European micro survey data prevents us from estimating the sector-specific Mincerian returns for countries in our sample.

${ }^{9}$ The database can be accessed through http://www. euklems.net/.
} 
the EU-KLEMS database is derived from national accounts of individual countries; and these countries follow a common European system of national and regional accounts (ESA95). ${ }^{10}$ Second, we restrict our sample to include only countries that were members of the European Union in 1995. The list of countries in our sample are: Austria, Belgium, Denmark, Finland, France, Germany, Greece, Ireland, Italy, Luxembourg, Netherlands, Portugal, Spain, Sweden, and United Kingdom. These fifteen countries have a longer, uninterrupted series of value added and employment for a large number of industries.

\subsection{Measures of Agricultural Productivity Gap}

In EU-KLEMS, the agriculture sector is defined as the sum of agriculture, hunting, forestry, and fishing. ${ }^{11}$ The non-agriculture sector comprises of all remaining industries. We calculate labor productivity in agriculture and non-agriculture for each country and each year. The agricultural productivity gap is defined as the ratio of labor productivity in non-agriculture to that in agriculture. For exposition purposes, we only report the agricultural productivity gap averaging over the sample period for each country. We present evidence later in this section that the productivity gap is very persistent over time for all countries; and hence our focus on the mean is innocuous.

We start with a conventional and straightforward measure of labor productivity: value added per worker, which is value added at current prices divided by number of people engaged in production. In EU-KLEMS, people engaged in production is the sum of employees (wage and salary workers) and self-employed. The agricultural productivity gap measured using value added per worker is quite large. Averaging across countries and over the sample period, the productivity gap is 2 . The difference in value added per worker is not a result of longer hours of work in non-agriculture relative to agriculture. Across all countries in

\footnotetext{
${ }^{10}$ For documentations of ESA95 and NACE, see http: //epp.eurostat.ec.europa.eu/statistics_explained.

${ }^{11}$ This definition is consistent with the one adopted by the Food and Agriculture Organization for measuring agriculture value added, and those used in Herrendorf and Schoellman (2012) and Gollin et al. (2013).
} 
our sample, people engaged in agricultural production work on average 38 hours per week, relative to 33 in non-agriculture. Consequently, when computed as the ratio of value added per hour in non-agriculture to that in agriculture, the agricultural productivity gap increases to 2.2. These agricultural productivity gaps documented for European countries are similar in magnitude to those previously documented for other developed countries. For example, Herrendorf and Schoellman (2012) found an average gap of 1.9 in value added per hour for US states; Gollin et al. (2013) found an average gap of 2 in value added per worker for the richest 25 percent countries in their sample.

Table 1: Labor Productivity: Non-agriculture relative to Agriculture

\begin{tabular}{lcc}
\hline Country & $\begin{array}{c}\text { Ratio of Value } \\
\text { Added per worker }\end{array}$ & $\begin{array}{c}\text { Ratio of Value } \\
\text { Added per hour }\end{array}$ \\
\hline AUT & 5.43 & 2.83 \\
BEL & 1.52 & 1.29 \\
DNK & 1.48 & 1.53 \\
ESP & 2.02 & 2.20 \\
FIN & 1.62 & 2.35 \\
FRA & 1.63 & 2.64 \\
GBR & 1.16 & 1.66 \\
GER & 2.35 & 2.76 \\
GRC & 2.99 & 2.78 \\
IRL & 1.59 & 2.13 \\
ITA & 2.17 & 3.18 \\
LUX & 1.94 & 2.06 \\
NLD & 1.18 & 1.52 \\
PRT & 2.76 & 2.90 \\
SWE & 1.08 & 1.35 \\
\hline Country Average & 2.06 & 2.21 \\
\hline
\end{tabular}

Table 1 reports the productivity gap averaging over the period 1970-2004 for each country in our sample. The second column lists the gaps in value added per worker, while the last column lists the gaps in value added per hour. We observe that for every country the productivity gap is above unity, indicating that labor productivity in non-agriculture is higher than that in agriculture. Further, even though these countries share similar levels 
of economic development, the productivity gap varies substantially across countries. When calculated as the ratio of value added per worker, it ranges from 1.1 in Sweden to 5.4 in Austria . For the value added per hour measure of the productivity gap, the range is from 1.3 in the Netherlands to 3.2 in Italy. ${ }^{12}$

The agricultural productivity gap is also persistent over time. To show this, we regress the agricultural productivity gap, measured using value added per worker and value added per hour, against a time trend (year), allowing for country-specific fixed effects. Table 2 summarizes the estimated coefficients from the regressions. The coefficient associated with year is not statistically significant for either measure of the agricultural productivity gap. Hence, we conclude that the agricultural productivity gap is persistent over time.

Table 2: Persistence of the Labor Productivity Gap

\begin{tabular}{lcc}
\hline & $\begin{array}{c}\text { Gap in Value Added } \\
\text { per worker }\end{array}$ & $\begin{array}{c}\text { Gap in Value Added } \\
\text { per hour }\end{array}$ \\
\hline year & 0.009 & 0.011 \\
& $(0.01)$ & $(0.009)$ \\
Observations & 520 & 520 \\
Countries & 15 & 15 \\
Fixed effects & Yes & Yes \\
\hline
\end{tabular}

Note: Robust standard errors in parentheses. Dependent variable is the gap in value added per worker and the gap in value added per hour.

\section{Sources of Agricultural Productivity Gap}

In this section we explore two possible explanations for the persistent agricultural productivity gaps documented for countries in our sample: mismeasurement of value added and differences in human capital between agriculture and non-agriculture.

\footnotetext{
${ }^{12}$ Note also that for Austria and Belgium, the gap in value added per hour is in fact smaller than the gap in value added per worker. In these two countries, average hours of work are lower in agriculture.
} 


\subsection{Measurement Problem and Adjustment}

Herrendorf and Schoellman (2012) argue that agricultural value added is substantially undermeasured in the US. In particular, they find that some components of agricultural value added are miscounted as value added in non-agriculture and that under-reporting of proprietor income is severe in agriculture. Are such measurement problems equally at play in Europe?

We use value added data, together with wage data, to identify potential measurement problems in value added. Following Herrendorf and Schoellman (2012), we use an accounting identity that relates value added per hour to wage. Let $w$ denote nominal wage, $H$ denote hours of work, and $Y$ denote nominal value added. Labor share of income, $L S$, is by definition equal to $(w \cdot H) / Y$. Now we consider the sectoral differences in these quantities. The ratio of value added per hour in non-agriculture $(n)$ to that in agriculture $(a)$ is given by

$$
\frac{\left(Y_{n} / H_{n}\right)}{\left(Y_{a} / H_{a}\right)}=\left(\frac{w_{n}}{w_{a}}\right) \cdot \frac{L S_{a}}{L S_{n}}
$$

The equation above states that the gap in value added per hour between agriculture and nonagriculture is proportional to the wage gap $\left(\frac{w_{n}}{w_{a}}\right)$. The proportionality is equal to the inverse of the ratio of labor income shares. We interpret the labor share as a structural parameter that does not vary across countries or over time. Existing empirical estimates of labor shares suggest that labor share in agriculture is approximately 44 percent (Hayami and Ruttan, 1970). For non-agriculture, the conventional value for labor share is 67 percent (Gollin, 2002). With these values for the labor shares, Equation (1) implies that the gap in value added per hour should be roughly 70 percent of the wage gap. This should hold regardless of assumptions about market structure. The question is whether this accounting identity holds in the data for countries in our sample.

To verify this, we calculate hourly wage in non-agriculture relative to that in agriculture 
from EU-KLEMS. ${ }^{13}$ We then compare the wage gap to the gap in value added per hour. To connect to Equation (1), we calculate the ratio of the gap in value added per hour to the wage gap, and call this statistic the gap ratio. Table 3 summarizes our findings. Averaging across countries and over the sample period, the gap ratio we find in the data is 1.26 , which is significantly higher than the theoretical value of 0.7 . Moreover, in no country is the gap ratio lower than 0.7 . In other words, relative to the theoretically predicted value, the gap in value added per hour is systematically higher than the wage gap for all countries in our sample.

Table 3: Gap in Value Added per hour and Wage Gap

\begin{tabular}{lccc}
\hline Country & $\begin{array}{c}\text { Gap in Value } \\
\text { Added per hour }\end{array}$ & Wage Gap & Gap Ratio \\
\hline AUT & 2.83 & 2.33 & \\
BEL & 1.29 & 1.37 & 0.9 \\
DNK & 1.53 & 2.06 & 0.8 \\
ESP & 2.20 & 2.64 & 0.8 \\
FIN & 2.35 & 2.01 & 1.2 \\
FRA & 2.64 & 1.83 & 1.5 \\
GBR & 1.66 & 1.85 & 0.9 \\
GER & 2.76 & 1.56 & 1.8 \\
GRC & 2.78 & 2.07 & 1.4 \\
IRL & 2.13 & 1.86 & 1.1 \\
ITA & 3.18 & 1.91 & 1.7 \\
LUX & 2.06 & 1.40 & 1.5 \\
NLD & 1.52 & 1.23 & 1.2 \\
PRT & 2.90 & 1.53 & 2.0 \\
SWE & 1.35 & 1.52 & 0.9 \\
\hline Country Average & 2.21 & 1.81 & 1.26 \\
\hline
\end{tabular}

Table 3 suggests that the accounting identity (1) does not hold in our data. We next examine whether mismeasurement of value added in national income accounts can explain why the accounting identity fails to hold. In particular, we explore the role of under-

\footnotetext{
${ }^{13}$ Hourly wage in each sector is calculated as total labor compensation divided by total hours of work. Since self-employed workers do not report wage, in EU-KLEMS they are assumed to receive the same hourly compensation as salaried employees. Lack of micro-data prevents us from imputing self-employed income based on observed characteristics such as age and education.
} 
reporting of self-employment income as a source of mismeasurement of value added. We provide two justifications for this approach. First, there is extensive evidence pointing to under-reporting of self-employment income in European countries. Pissarides and Weber (1989) found that for Britain average true self-employed income is 1.55 times as much as reported self-employed income. Similar magnitude of under-reporting was documented for Italy by Fiorio and D'Amuri (2005), and for Greece by Matsaganis and Flevotomou (2010). Though under-reporting of self-employment income is present in all sectors of an economy, the problem of under-reporting is found to be more severe in agriculture. For example, Matsaganis and Flevotomou (2010) found that true farm income is more two times higher than reported income for Greece. Second and importantly, under-reporting of selfemployment income leads to under-measurement of value added, and more so in agriculture than in non-agriculture. This is because self-employment is more dominant in agriculture. Figure 1 plots on the vertical axis the gap ratio calculated from the data, and on the horizonal axis the self-employment share of hours in agriculture. The figure depicts a strong correlation between the two variables. In other words, in cases where self-employment supplies a higher share of total hours in agriculture, the gap ratio is higher and deviates more significantly from the theoretical value of 0.7 .

We now perform a series of adjustment to value added data from national accounts to correct for under-reporting of self-employment income. In each case, we compute an adjusted agricultural productivity gap. To illustrate our approach, let $Y_{s}$ and $Y_{e}$ denote the measured value added of self-employed and employees in a particular sector, and $H_{s}$ and $H_{e}$ their respective hours of work. Then measured value added per hour for the sector is $\frac{Y_{s}+Y_{e}}{H_{s}+H_{e}}$. If value added from self-employment is under-measured by a factor $\psi>1$, the adjusted value added per hour is

$$
\frac{\psi Y_{s}+Y_{e}}{H_{s}+H_{e}} .
$$


Figure 1: Gap Ratio and Self-employment Share of Hours in Agriculture

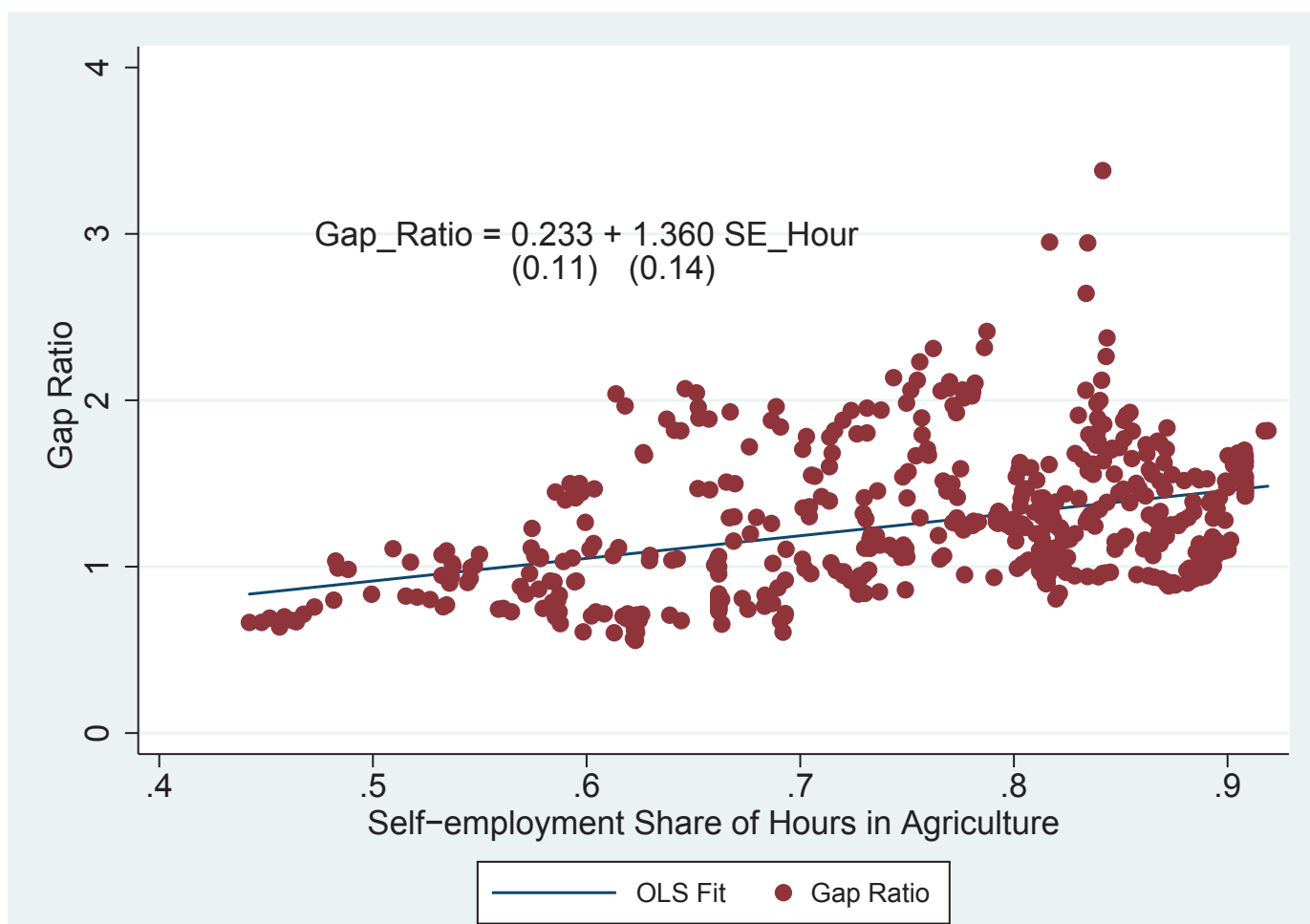

Note: Each point on the figure represents a gap ratio for one country in a particular year. The regression equation is presented on the figure with robust standard errors in parenthesis.

EU-KLEMS has data on $H_{s}$ and $H_{e}$ but does not provide $Y_{s}$ and $Y_{e}$. To overcome this data limitation, we make a simplifying assumption that value added per hour for self-employed is equal to that of employees within a sector. In other words, it is assumed that for each sector $Y_{s} / H_{s}=Y_{e} / H_{e}=\left(Y_{s}+Y_{e}\right) /\left(H_{s}+H_{e}\right)$. Given this, rearranging the terms provides the adjustment factor as follows:

$$
\frac{\psi Y_{s}+Y_{e}}{Y_{s}+Y_{e}}=\frac{\psi \frac{Y_{s}}{H_{s}} H_{s}+\frac{Y_{e}}{H_{e}} H_{e}}{\frac{Y_{s}}{H_{s}} H_{s}+\frac{Y_{e}}{H_{e}} H_{e}}=\frac{\psi H_{s}+H_{e}}{H_{s}+H_{e}} .
$$

That is, to account for under-reporting of self-employment income, value added per hour in each sector should be adjusted upward by a factor equal to $\frac{\psi H_{s}+H_{e}}{H_{s}+H_{e}}$. The adjustment 
factor is an increasing function of the fraction of self-employed hours $\left(H_{s} /\left(H_{e}+H_{s}\right)\right)$ and differs between agriculture and non-agriculture. Across countries, the average fraction of self-employment hours is 75 percent in agriculture, compared to only 14 percent in nonagriculture.

To compute the adjusted value added per hour, we use EU-KLEMS data on $H_{s}$ and $H_{e}$ for agriculture and non-agriculture and experiment with different values of $\psi$. We consider three values: $\psi=1.5,2.2$, and 3 . The first value is the average magnitude of under-reporting in Britain reported by Pissarides and Weber (1989). The second value corresponds to the degree of under-reporting in farming reported for Greece by Matsaganis and Flevotomou (2010). ${ }^{14}$ We also consider a third value of 3 as an upper bound for the magnitude of under-reporting.

For each value of $\psi$, we compute adjusted value added per hour in both agriculture and non-agriculture. Table 4 reports the average gap in value added per hour after adjusting for self-employment income for each country. The immediate observation is that the adjustment has a large impact on the magnitude of measured agricultural productivity gap. An adjustment factor of 1.5 yields a 30 percent reduction in the average productivity gap, from 2.2 to 1.7. With an adjustment factor of 2.2 , the average productivity gap further reduces to 1.24. These results suggest that in the case of European countries, under-reporting of selfemployment income can have a substantial impact on measured agricultural productivity gap.

We now revisit the relation between the gap in value added per hour and the wage gap, that is, the gap ratio. In Table 3, we documented that the gap ratio calculated from the data is much larger than the theoretical value of 0.7. Since our adjustment for under-reporting of self-employment income reduces the gap in value added per hour, it follows that the gap

\footnotetext{
${ }^{14}$ For the US, Herrendorf and Schoellman (2012) also experiment with a factor of 2.3 to adjust proprietor income in agriculture.
} 
Table 4: Gap in Value Added per hour After Adjustment

\begin{tabular}{|c|c|c|c|c|c|}
\hline & & \multicolumn{3}{|c|}{$\begin{array}{c}\text { Gap in Value Added } \\
\text { per hour after adjustment }\end{array}$} & $\begin{array}{c}\text { Adjusted } \\
\text { Gap Ratio }\end{array}$ \\
\hline & Data & $\psi=1.5$ & $\psi=2.2$ & $\psi=3$ & $\psi=2.2$ \\
\hline$\overline{\text { AUT }}$ & 2.83 & 2.07 & 1.45 & 1.08 & 0.62 \\
\hline BEL & 1.29 & 0.98 & 0.70 & 0.52 & 0.51 \\
\hline DNK & 1.53 & 1.23 & 0.94 & 0.73 & 0.47 \\
\hline ESP & 2.20 & 1.76 & 1.30 & 1.00 & 0.49 \\
\hline FIN & 2.35 & 1.76 & 1.25 & 0.94 & 0.65 \\
\hline FRA & 2.64 & 1.98 & 1.41 & 1.06 & 0.78 \\
\hline GBR & 1.66 & 1.40 & 1.09 & 0.86 & 0.59 \\
\hline GER & 2.76 & 2.19 & 1.63 & 1.26 & 1.05 \\
\hline GRC & 2.78 & 2.27 & 1.59 & 1.18 & 0.79 \\
\hline IRL & 2.13 & 1.62 & 1.15 & 0.87 & 0.61 \\
\hline ITA & 3.18 & 2.67 & 1.94 & 1.48 & 1.04 \\
\hline LUX & 2.06 & 1.51 & 1.07 & 0.80 & 0.76 \\
\hline NLD & 1.52 & 1.18 & 0.85 & 0.64 & 0.69 \\
\hline PRT & 2.90 & 2.17 & 1.54 & 1.16 & 1.05 \\
\hline SWE & 1.35 & 1.05 & 0.78 & 0.60 & 0.51 \\
\hline Country Average & 2.21 & 1.72 & 1.24 & 0.95 & 0.71 \\
\hline
\end{tabular}

ratio will be reduced as well. The last column of Table 4 provides the adjusted gap ratio for each country for $\psi=2.2$. The average adjusted gap ratio is 0.71 , which is consistent with the theoretical prediction for the gap ratio. In addition, in most countries the adjusted gap ratio is in a close ballpark of 0.7 . Furthermore, we examine the gap ratio over time in Figure 2, which plots for each year the cross-country average gap ratio measured from the data and the adjusted gap ratio for $\psi=1.5$ and $\psi=2.2$. The figure clearly indicates that for $\psi=2.2$, the average adjusted gap ratio is very close to 0.7 for all years.

We now discuss our findings and put them in perspective. Our main finding so far is that under-reporting of self-employment income can lead to measured agricultural productivity gaps that are significantly inflated. Our results hence complement those established in Herrendorf and Schoellman (2012) for the US. Taken together, these findings point to measurement issues that appear common in national income and product accounts of developed 
Figure 2: Measured and Adjusted Gap Ratio: Cross-Country Average 1970-2004

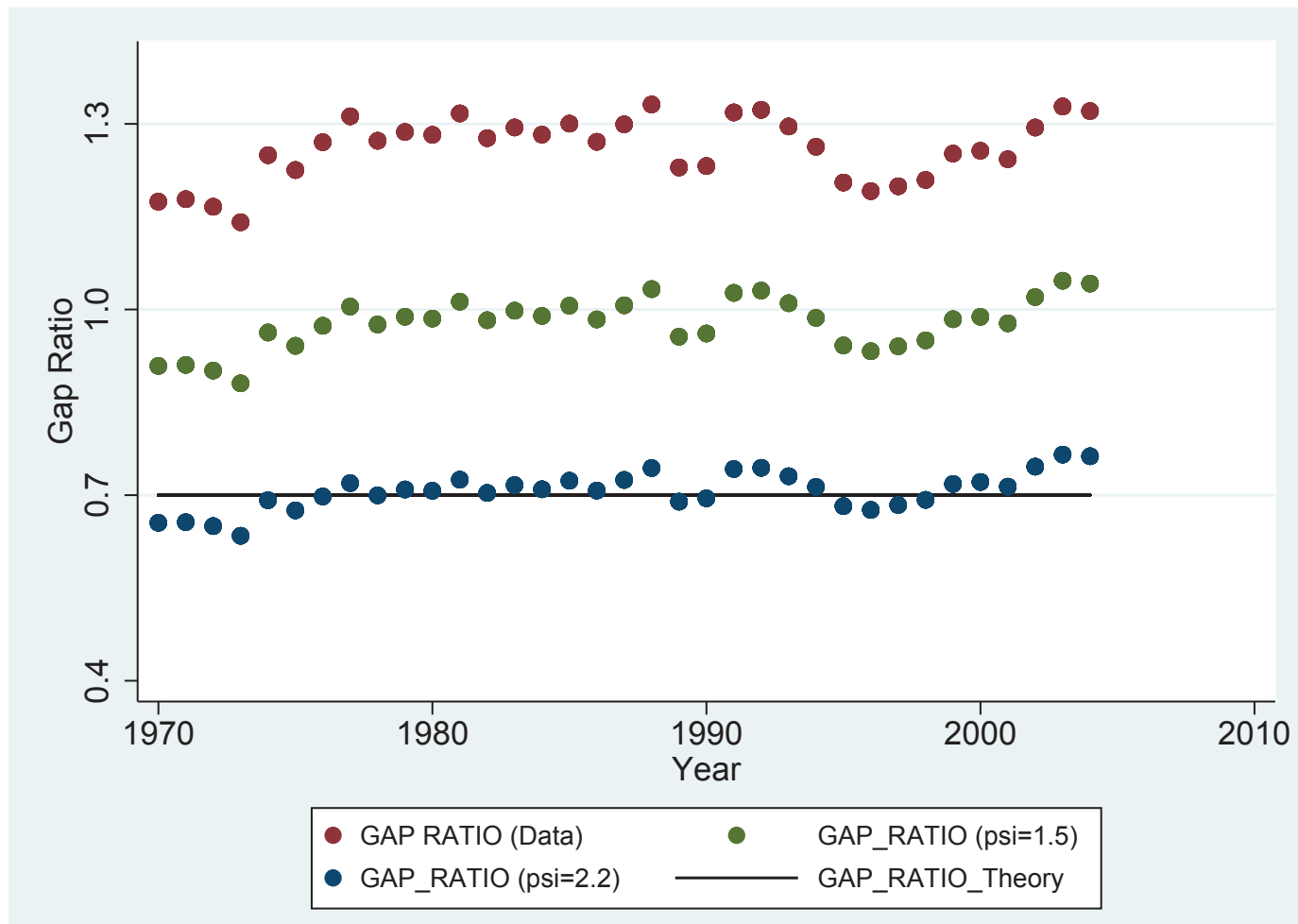

countries. However, our results should be interpreted as suggestive rather than conclusive, for several reasons. Firstly, our identification of measurement problems in value added was organized around an accounting identity that relates value added per hour to wage. Implicitly, we have assumed that wage data is not subject to measurement problems because it is aggregated from micro-level labor force surveys. This is largely true except for the caveat that self-employed individuals do not report wage. In EU-KLEMS, self-employed are assumed to earn the same hourly compensation as employees within the same sector. This assumption bears little implication for the non-agriculture sector because (1) self-employment is less than 10 percent of the labor force and (2) non-agriculture comprises of a large array of industries, over which potential differences in wage between self-employed and employees will likely even out.

For agriculture, measured wage will be sensitive to this assumption because in most 
countries self-employed constitute more than 50 percent of the labor force in agriculture. Moreover, if there is positive self-selection into self-employment in agriculture (e.g., more educated people are more likely to be self-employed), then the embedded assumption in EU-KLEMS is likely to bias downward measured average wage in agriculture. We argue, however, that failure to take this into account does not invalidate our identification of measurement problems in value added. Suppose agricultural wage is corrected for unobserved characteristics that drive a positive self-selection, which yields a smaller wage gap between agriculture and non-agriculture. This would also imply that the ratio of the gap in value added per hour to the wage gap will be even larger, which would be a stronger indication of measurement problems in value added.

Secondly, while there are extensive evidence pointing to under-reporting of self-employment income, quantifying the magnitude of under-reporting remains a challenge. The numbers we used to correct for under-reporting, while being in the range of existing empirical estimates, are rather arbitrary in nature. Consequently, our results are exploratory at best. Lastly, our adjustment of self-employment income implicitly assumes that such correction has not been done by the relevant statistics agency. For example, Herrendorf and Schoellman (2012)

point out that the Bureau of Economic Analysis adjusts proprietor income based on tax records when computing value added in non-agriculture. Based on documentation provided for the EU-KLEMS database and to the best of our knowledge, we are not aware of any such correction in place for European countries in our sample.

\subsection{Human Capital}

As we have shown, correcting for under-reporting of self-employment income has a substantial impact on measured labor productivity difference between agriculture and non-agriculture. It is, however, rather challenging to say that the measured agricultural productivity gap is entirely due to mismeasurement of value added. Even with our preferred correction factor 
of 2.2, the average gap in value added per hour between agriculture and non-agriculture remains at 1.24. In this section, we explore whether sectoral differences in human capital might contribute to the agricultural productivity gap.

We construct measures of human capital for each sector using Mincerian returns to schooling and experience. First, using data on skill levels of workers in EU-KLEMS we impute average years of schooling in agriculture and non-agriculture for each country. ${ }^{15}$ Average years of schooling is lower in agriculture than in non-agriculture for all countries. Further, using information on sector-specific age distribution of workers in EU-KLEMS, we impute the average years of experience in agriculture and non-agriculture.

To compute sector-specific measures of human capital using schooling and experience, we need information on returns to schooling and experience. Importantly, these returns might differ between agriculture and non-agriculture. For example, Lagakos et al. (2013) show that age-earnings profile differs substantially between agriculture and non-agriculture. Hence, abstracting from sectoral heterogeneity in returns would bias the measure of sectoral differences in human capital. Given that there are no existing estimates of sector-specific Mincerian returns for countries in our sample, we estimate these returns using data for the US. ${ }^{16}$ We assume that returns to education and experience for countries in our sample are the same as those for the US.

We calculate human capital following the standard development accounting approach as in Klenow and Rodriguez-Clare (1997) and Hall and Jones (1999). Specifically, the average person working in sector $i$ with $s$ years of schooling and $e$ years of experience has human capital $h_{i}$ given by $h_{i}=\exp \left(\beta_{1}^{i} \cdot s+\beta_{2}^{i} \cdot e+\beta_{3}^{i} \cdot e^{2}\right)$, where $\beta_{j}^{i}$ are sector-specific returns to

\footnotetext{
${ }^{15} \mathrm{~A}$ detailed description of how we impute average years of schooling and experience is provided in the Appendix. EU-KLEMS does not provide data on skill composition of workers for the following four countries: Greece, Ireland, Luxembourg and Portugal. We could not compute sector-specific human capital for these countries.

${ }^{16} \mathrm{~A}$ detailed description of how we estimate the returns using US data, as well as the regression output are provided in the Appendix.
} 
schooling, experience, and experience squared. Table 5 reports the ratio of human capital in non-agriculture to that in agriculture by country, averaging over the sample period. We find that people working in non-agriculture indeed have higher human capital than those in agriculture. The average gap in human capital is a factor 1.2. Two related comments are in order. First, the gap in human capital suggests that in an economy with competitive labor markets, there will be differences in labor productivity between agriculture and nonagriculture, i.e., agricultural productivity gap. Second, to appreciate the magnitude of the sectoral differences in human capital, recall that the gap in value added per hour after adjusting upward self-employment income by a factor $\psi=2.2$ is 1.24 . That is, the sectoral differences in human capital are similar in magnitude to the gap in value added per hour after adjusting self-employment income. ${ }^{17}$

Table 5: Human Capital: Non-agriculture relative to Agriculture

\begin{tabular}{lc}
\hline Country & $\begin{array}{c}\text { Gap in } \\
\text { Human Capital }\end{array}$ \\
\hline AUT & 1.20 \\
BEL & 1.20 \\
DNK & 1.18 \\
ESP & 1.17 \\
FIN & 1.23 \\
FRA & 1.20 \\
GBR & 1.20 \\
GER & 1.21 \\
ITA & 1.20 \\
NLD & 1.23 \\
SWE & 1.19 \\
\hline Country Average & 1.20 \\
\hline
\end{tabular}

\footnotetext{
${ }^{17}$ Another notable observation from Table 5 is that the human capital gap varies minimally across countries, compared to the gap in value added per hour. There are two reasons for this. First, the sectoral differences in years of schooling and experience do not vary a lot across countries. Second, by using the US Mincerian returns for all countries, we have assumed that sectoral differences in returns to education and experience are the same across countries.
} 


\section{Conclusion}

Research on the agricultural productivity gap - labor productivity difference between agriculture and non-agriculture within a country - has analyzed the role of mismeasurement of value added in explaining the productivity gap. Gollin et al. (2013) focus primarily on developing nations and argue that measurement problems in national account are not important for explaining the enormous measured productivity gaps recorded for those countries. However, Herrendorf and Schoellman (2012) find that the agricultural productivity gaps across US states is primarily due to mismeasurement of value added in national accounts. We contribute to this debate by examining the agricultural productivity gap for a set of European countries, and find that agricultural productivity gaps in Europe are remarkably similar to those recorded for US states. We also find that under-reporting of self-employment can lead to measured agricultural productivity gaps that are significantly inflated. Correcting for the

under-reporting can halve the measured agricultural productivity gap. Lastly, we explore sectoral differences in human capital and find that sectoral differences in human capital are similar in magnitude to the residual agricultural productivity gap, after adjusting for self-employment income. Our findings suggest that measured labor productivity differences between agriculture and non-agriculture in European countries are not an indicator of resource misallocation, but possibly an artifact of mismeasurement of value added and sectoral differences in human capital.

\section{References}

Adamopoulos, T. (2011). Transportation Costs, Agricultural Productivity and CrossCountry Income Differences. International Economic Review 52(2).

Adamopoulos, T. and D. Restuccia (2013). The Size Distribution of Farms and International 
Productivity Differences. American Economic Review, Forthcoming.

Cai, W. (2012). Skill Accumulation and Sectoral Productivity Differences Across Countries. Manuscript, University of Winnipeg.

Caselli, F. (2005). Accounting For Cross Country Income Differences. In P. Aghion and S. D. Durlauf (Eds.), Handbook of Economic Growth, pp. 679-741. ELSEVIER.

Donovan, K. (2013). Agricultural Risk, Intermediate Inputs, and Cross-Country Productivity Differences. Working Paper, University of Notre Dame.

Fiorio, C. V. and F. D'Amuri (2005). Workers' Tax Evasion in Italy. Giornale degli Economisti e Annali di Economia 64(2/3), 247-270.

Gollin, D. (2002). Getting Income Shares Right. Journal of Political Economy 110(2), $458-474$.

Gollin, D., D. Lagakos, and M. E. Waugh (2013). The Agricultural Productivity Gap. Quarterly Journal of Economics. Forthcoming.

Gollin, D., S. L. Parente, and R. Rogerson (2004). Farm work, Home Work and International Productivity Differences. Review of Ecconomic Dynamics 7(4), 827-850.

Gollin, D. and R. Rogerson (2010). Agriculture, Roads, and Economic Development in Uganda. Working Paper 15863, National Bureau of Economic Research.

Hall, R. E. and C. I. Jones (1999). Why Some Countries Produces So Much More Output per Worker Than Others. The Quaterly Journal of Economics 114(1), 83-116.

Hayami, Y. and V. W. Ruttan (1970). Agricultural Productivity Differences among Countries. The American Economic Review 60(5), 895-911. 
Herrendorf, B. and T. Schoellman (2012). Why Is Measured Productivity so Low in the Agriculture. Working Paper, Arizona State University.

Klenow, P. and A. Rodriguez-Clare (1997). The Neoclassical Revival in Growth Economics: Has It Gone Too Far? In B. Bernanke and J. Rotemberg (Eds.), NBER Macroeconomics Annual 1997, Volume 12, pp. 73-114. MIT Press.

Lagakos, D., B. Moll, T. Porzio, and N. Qian (2013). Experience Matters: Human Capital and Development Accounting. Manuscript, Princeton University.

Lagakos, D. and M. E. Waugh (2013). Selection, Agriculture, and Cross-Country Productivity Differences. American Economic Review 103(2), 948-80.

Matsaganis, M. and M. Flevotomou (2010). Distributional Implications of Tax Evasion in Greece. GreeSE Hellenic Observatory Papers on Greece and Southeast Europe 31, Hellenic Observatory, LSE.

O'Mahony, M. and M. P. Timmer (2009). Output, input and productivity measures at the industry level: The eu klems database. Economic Journal 119(538), 374-403.

Pissarides, C. A. and G. Weber (1989). An expenditure-based estimate of Britain's black economy. Journal of Public Economics 39(1), 17-32.

Restuccia, D., D. T. Yang, and X. Zhu (2008). Agriculture and Aggregate Productivity: A Quantitative Cross-country Analysis. Journal of Moneytary Economics 55(2), 234-250.

Vollrath, D. (2009). How Important are Dual Economy Effects for Aggregate Productivity? Journal of Development Economics 88(2), 325-334.

Young, A. (2013). Inequality, the Urban-Rural Gap, and Migration. The Quarterly Journal of Economics 128(4), 1727-1785. 


\section{APPENDIX}

\section{A Mincerian Returns From CPS}

We use data for the US from March Supplement to the 2012 Current Population Survey (CPS) for estimating sector-specific returns to eduction and experience. We restrict our sample to include individuals between age 25 and 65, who work more than 20 hours per week and have positive earnings. Earnings are calculated as the sum of wage and salary, business income, and farm income. We then regress log hourly earnings on years of schooling, experience, and experience squared, separately for individuals working in agriculture and non-agriculture. ${ }^{18}$ The coefficients associated with the regressions are provided in Table 6.

Table 6: Mincerian Regression Results (US CPS Data)

\begin{tabular}{lllll}
\hline & \multicolumn{4}{l}{ Robust } \\
logy & Coef. & Std. Err. & $\mathrm{t}$ & $\mathrm{P}>\mathrm{t}$ \\
\hline edu & 0.107 & 0.001 & 100.650 & 0.000 \\
expr & 0.031 & 0.001 & 26.890 & 0.000 \\
expr2 & -0.0004 & 0.00002 & -20.020 & 0.000 \\
ind $\times$ edu & -0.040 & 0.007 & -5.920 & 0.000 \\
ind $\times$ expr & 0.018 & 0.007 & 2.630 & 0.009 \\
ind $\times$ expr2 & 0.0003 & 0.0001 & -2.280 & 0.023 \\
cons & 1.181 & 0.021 & 57.260 & 0.000 \\
\hline
\end{tabular}

Note: logy is logarithm of hourly earnings; edu is years of education; expr is years of experience; expr2 is experience squared; ind is an industry dummy that takes value 1 for agriculture, and 0 otherwise; ind $\times e d u$ is the interaction between industry and years of schooling; ind $\times$ expr is the interaction between industry and years of experience; ind $\times$ expr2 is the interaction between industry and experience squared.

\section{B Years of Schooling and Experience from EU-KLEMS}

Years of Schooling EU-KLEMS data report hours worked by skill level: high-skilled, medium-skilled, and low-skilled. Skill is defined based on educational attainment. The

\footnotetext{
${ }^{18}$ Years of experience is imputed as age - years of schooling -6 .
} 
definition of educational attainment is consistent over time within a country, but might differ across countries. In most cases, high-skilled individuals have university degrees or more. Low-skilled individuals have no more than primary education. Medium-skilled individuals have educational attainment somewhere between primary and university education. To map skill level to years of schooling, we assume that low, medium, and high skill levels are associated with 6, 10 and 14 years of schooling. Table 7 reports the average years of schooling in agriculture and non-agriculture by country. Table 8 lists for each country the relevant labor force surveys that provide these information. Table 9 lists the mapping between skill level and the educational attainment for each country.

Years of Experience EU-KLEMS also reports hours worked by age groups: <29, 29-49, and $>50$. To compute the average age for each sector, we assume the mid-point of each age bin is the average age for the respective group. We find that individuals working in agriculture are significantly older than those in non-agriculture. The average age is 43 in agriculture, compared to 38 in non-agriculture. Following the standard development accounting practice, we then impute years of experience $=$ age - years of schooling -6 .

Table 7: Average Years of Schooling in Agriculture and Non-agriculture

\begin{tabular}{lcc}
\hline Country & Agriculture & Non-Agriculture \\
\hline AUT & 7.9 & 9.3 \\
BEL & 7.3 & 8.9 \\
DNK & 7.3 & 8.8 \\
ESP & 6.4 & 8.1 \\
FIN & 8.7 & 9.4 \\
FRA & 7.9 & 9.2 \\
GBR & 8.1 & 9.1 \\
GER & 8.8 & 9.0 \\
ITA & 9.3 & 10.2 \\
NLD & 9.6 & 10.5 \\
SWE & 8.7 & 9.5 \\
\hline Country Average & 8.2 & 9.3 \\
\hline
\end{tabular}


Table 8: Data Source for Employment and Labor Compensation

\begin{tabular}{|c|c|c|c|}
\hline \multirow[t]{2}{*}{ Country } & \multirow[t]{2}{*}{ Country Code } & \multicolumn{2}{|c|}{ Source of Data } \\
\hline & & Employment & Compensation \\
\hline Austria & AUT & $\begin{array}{l}\text { Microcensus for 1980-2003 } \\
\text { Census of Population for } 1991 \text { and } 2001\end{array}$ & $\begin{array}{l}\text { Microcensus for } 1997 \text {; } \\
\text { Time series from wage and salary statistics }\end{array}$ \\
\hline Belgium & BEL & $\begin{array}{l}\text { Unpublished social security data for } 1997-2004 \\
\text { Minstry of Labor and LFS data for prior } 1970\end{array}$ & $\begin{array}{l}\text { Unpublished Social Security Data } \\
\text { Structure of Earnings Survey; LFS }\end{array}$ \\
\hline Denmark & DNK & Administrative data from 1980-2003 & Administrative data from 1980-2003 \\
\hline Spain & ESP & Labour Force Survey & Wage Structure Survey \\
\hline Finland & FIN & Statistics Finland longitudinal census & Statistics Finland longitudinal census \\
\hline France & FRA & $\begin{array}{l}\text { Labour force surveys: } 1982-1989,1990-2002 \text {, } \\
\text { 2003, } 2004\end{array}$ & $\begin{array}{l}\text { Labour force surveys: 1982-1989, 1990-2002, } \\
\text { 2003, } 2004\end{array}$ \\
\hline United Kingdom & GBR & $\begin{array}{l}\text { Labour Force Survey 1979-2004 } \\
\text { General Household Survey 1974-80 }\end{array}$ & $\begin{array}{l}\text { Labour Force Survey 1993-2004 } \\
\text { General Household Survey 1972-1993/94 }\end{array}$ \\
\hline Germany & GER & $\begin{array}{l}\text { Income survey, social security data } \\
\text { Socio-Economic Panel Study, } \\
\text { supplemented with micro data }\end{array}$ & $\begin{array}{l}\text { Income survey, social security data } \\
\text { Socio-Economic Panel Study, } \\
\text { supplemented with micro data }\end{array}$ \\
\hline Italy & ITA & $\begin{array}{l}\text { Census of population of } 1971,1981 \text {, } \\
1991 \text {, and } 2001\end{array}$ & $\begin{array}{l}\text { Bank of Italy surveys on households income, } \\
1977-2004\end{array}$ \\
\hline Netherland & NLD & $\begin{array}{l}\text { System of Labour Accounts } \\
\text { Labour Force Sample Survey (LFSS) } \\
\text { Labour Force Survey (LFS) }\end{array}$ & $\begin{array}{l}\text { Wage Structure for } 1979,1985,1989 \text {, } \\
1996,1997 \text {, and } 2002 \\
\text { Inquiry of Work Conditions for } 1992-2002 \\
\text { by Ministry of Social Affairs and Employment }\end{array}$ \\
\hline Sweden & SWE & Statistics Sweden, employment at A60 level & Statistics Sweden \\
\hline
\end{tabular}


Table 9: Mapping Between Skill and Education

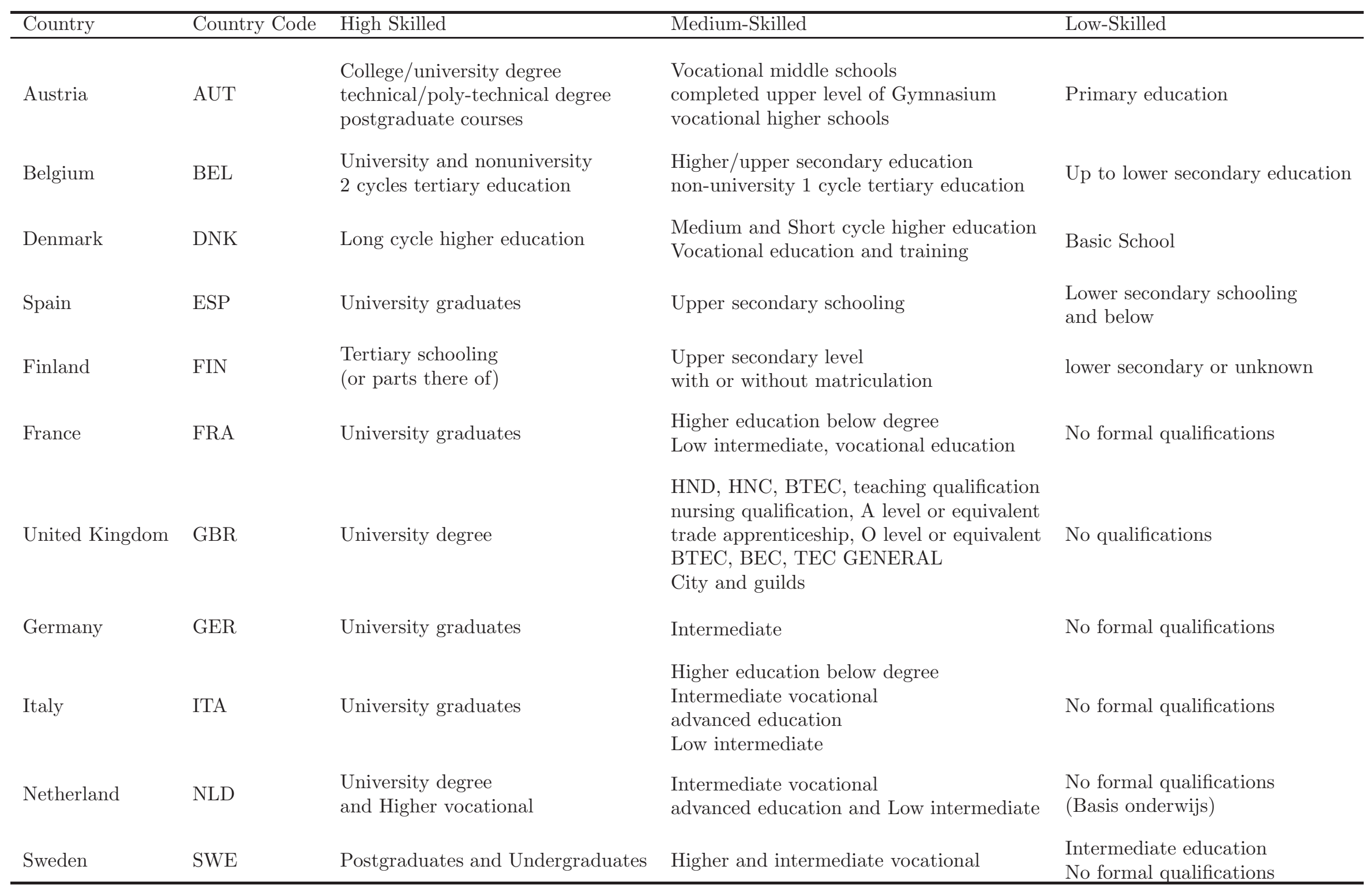

